\title{
Publisher Correction: The RNA Atlas expands the catalog of human non-coding RNAs
}

Lucia Lorenzi, Hua-Sheng Chiu (D), Francisco Avila Cobos (D), Stephen Gross (1), Pieter-Jan Volders (1), Robrecht Cannoodt (1), Justine Nuytens (1), Katrien Vanderheyden, Jasper Anckaert (D), Steve Lefever (D), Aidan P. Tay (D, Eric J. de Bony (D),

Wim Trypsteen (D), Fien Gysens (D), Marieke Vromman (1), Tine Goovaerts, Thomas Birkballe Hansen (D), Scott Kuersten,

Nele Nijs (D), Tom Taghon (D), Karim Vermaelen (1), Ken R. Bracke (D), Yvan Saeys (D), Tim De Meyer (D),

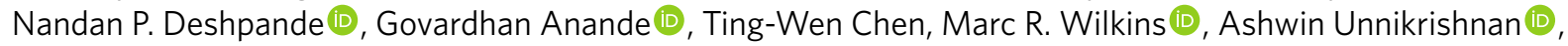

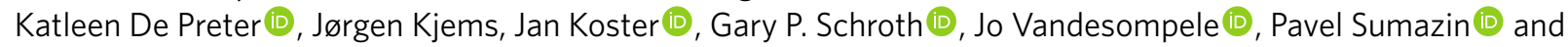

Pieter Mestdagh (10)

Correction to: Nature Biotechnology https://doi.org/10.1038/s41587-021-00936-1, published online 17 June 2021.

In the version of this article initially published online, Pavel Sumazin's affilation was given as Cancer Research Institute Ghent (CRIG), Ghent, Belgium. The correct affiliation is Texas Children's Cancer Center, Baylor College of Medicine, Houston, TX, USA. The error has been corrected in the print, PDF and HTML versions of the article.

Published online: 28 June 2021

https://doi.org/10.1038/s41587-021-00996-3

๑ The Author(s), under exclusive licence to Springer Nature America, Inc. 2021

\section{Publisher Correction: Measurement of histone replacement dynamics with genetically encoded exchange timers in yeast}

Gilad Yaakov $\mathbb{D}$, Felix Jonas $(\mathbb{D}$ and Naama Barkai $(\mathbb{D}$

Correction to: Nature Biotechnology https://doi.org/10.1038/s41587-021-00959-8, published online 8 July 2021.

In the version of this Article initially published, there was an error in Fig. 3. Specifically, in Fig. 3a, the lower blue equation at left, the denominator in the final term was a duplication of the second-to-last term, mistakenly reading " $k$ off $+k c l v$ " when it should have been

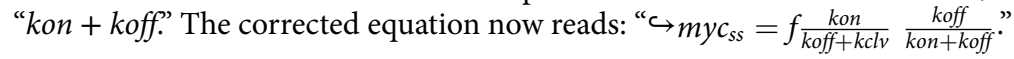

The changes have been made to the print and online versions of the Article.

Published online: 28 September 2021

https://doi.org/10.1038/s41587-021-01103-2

(c) The Author(s), under exclusive licence to Springer Nature America, Inc. 2021

\section{Publisher Correction: Oncologists greet Lumakras: the world's first KRAS inhibitor}

\section{Cormac Sheridan}

Correction to: Nature Biotechnology https://doi.org/10.1038/s41587-021-01053-9, published online 9 September 2021.

In the version of this News article initially published, the article should have stated that in addition to Qiagen's Therascreen, the FDA also approved Guardant360 CDx from Guardant Health, as companion diagnostics for Lumakras. In the fourth paragraph, in the third sentence beginning "It is approved for use with a companion diagnostic," the end of the sentence has been amended to include "or Guardant360 CDx from Guardant Health."

The online version of the article has been updated.

Published online: 12 October 2021

https://doi.org/10.1038/s41587-021-01120-1

(c) The Author(s), under exclusive licence to Springer Nature America, Inc. 2021 